\title{
Evaluation of the Extent and Potential Impacts of Noise Pollution inside Public Service Vehicles (PSVs) in Nairobi City, Kenya
}

\author{
Dancan Otieno Onyango ${ }^{1,}$, , Chritopher L. Kanali ${ }^{2}$, James Wambua Kaluli ${ }^{1}$ \\ ${ }^{1}$ Department of Soil, Water and Environmental Engineering, Jomo Kenyatta University of Agriculture and Technology, Nairobi, Kenya \\ ${ }^{2}$ Department of Biomechanical and Processing Engineering, Jomo Kenyatta University of Agriculture and Technology, Nairobi, Kenya
}

\section{Email Address:}

dancanthomas@gmail.com (D. O. Onyango),c_kanali@yahoo.com (C. L. Kanali),wambuak@gmail.com (J. W. Kaluli)

\section{To cite this article:}

Dancan Otieno Onyango, Chritopher L. Kanali, James Wambua Kaluli. Evaluation of the Extent and Potential Impacts of Noise Pollution inside Public Service Vehicles (PSVs) in Nairobi City, Kenya. American Journal of Environmental Protection.

Vol. 4, No. 5, 2015, pp. 260-270. doi: 10.11648/j.ajep.20150405.17

\begin{abstract}
Public service vehicles (PSVs) in Nairobi City, Kenya, have a tendency of playing loud music inside the vehicles resulting in disturbing noise. The objective of this study was to evaluate the extent of noise pollution inside PSVs in Nairobi City and predict possible impacts of the noise on PSV users. A sample of 60 randomly selected PSVs were analyzed. Posing as passengers inside the vehicles, noise measurements were taken using a digital integrating sound level meter (SVANTEK 971) inside these matatus. The measured noise levels were compared with corresponding legislated limits and the deviation thereof used to quantify the extent of pollution and probe the effectiveness of existing noise laws. Additionally, potential effects of the noise were predicted by comparing measured noise levels with respective guidelines recommended to protect public health and welfare from various adverse impacts of noise. The study results showed that PSV users in Nairobi are exposed to $86.3 \pm 9.6 \mathrm{~dB}$ A of noise inside PSVs and all the sampled vehicles did not comply with Kenyan noise regulations. PSVs plying northern Nairobi area were found to be the noisiest at $92.2 \pm 9.4 \mathrm{dBA}$, followed by Nairobi West PSVs at 88.7 $\pm 9.6 \mathrm{dBA}$; Nairobi South PSVs at $83.1 \pm 6.3 \mathrm{dBA}$ and Nairobi East PSVs at $81.2 \pm 7.7 \mathrm{dBA}$. The growing habit of PSVs playing extremely loud music/radio using sound amplifying equipment, was found to be a major contributor to noise pollution inside the vehicles, in addition to normal vehicular traffic sounds. The high noise levels put city dwellers at risk of such adverse effects of noise as noise-induced hearing loss (NIHL); physiological and psychological noise effects; speech interference, sleep disturbance; annoyance, social and behavioral effects. This calls not only for intensified noise law enforcement in the city, but also puts to question the effectiveness of existing noise laws to control noise in the city.
\end{abstract}

Keywords: Noise, Noise Pollution, Public Service Vehicles, Noise Impacts

\section{Introduction}

Noise is defined in Kenyan law as "any undesirable sound that is intrinsically objectionable or that may cause adverse effects on human health or damage to the environment". The law goes further to define noise pollution as "the emission of uncontrolled noise that is likely to cause danger to human health or damage the environment" [1, p.3]. Generally, noise pollution is recognized in three categories: community noise, industrial noise and airport noise. Industrial noise and airport noise refer to noise emanating from industrial processes and airport operations, respectively, whereas community noise (or environmental noise) is noise emanating from human activities such as transportation, recreation, entertainment, worship, businesses, animal rearing, construction and internal domestic activities [2]

In Kenya, not much has been done to study noise pollution. However, in 2009, the noise problem was recognized and the Noise and Excessive Vibration (Pollution) Control Regulations, 2009 (hereafter referred to as the Noise Act or Legal Notice Number 61) enacted. This legislation, annexed to the Environmental Management and Coordination Act, EMCA, 1999, provides for relevant noise criteria for different environments and empowers the National Environment Management Authority (NEMA) to enforce the noise regulations. NEMA has singled out noise pollution as an issue of grave environmental concern [3] in Kenya, particularly in major urban centers such as Nairobi, Kisumu, 
Mombasa and Eldoret, among others. In addition to NEMA, the Directorate of Occupational Safety and Health Services (DOSHS) is tasked with protecting workers from occupational noise.

Despite attempts by NEMA and DOSHS to control noise in Kenya, community noise remains a nuisance and a major health risk factor in Nairobi City. This is due to rapid industrialization, population pressure and growth in commercial, entertainment, transportation and religious activities in the city. The public transport sector, specifically, is a notorious source of noise. As a matter of fact, a walk through the city streets and estates reveals alarming noise levels from moving PSVs (popularly known as Matatus). The situation is exacerbated by a growing habit of PSVs playing extremely loud music/radio in the vehicles. This is aided by the use of sophisticated sound amplifying equipment and numerous loud speakers installed everywhere inside the PSVs. In essence, the resulting high noise renders telephone or speech communication practically impossible while traveling in the PSVs. Additionally, the PSVs are accustomed to uncontrolled hooting and touting (PSV crew shouting and banging vehicle bodies), particularly as they approach bus termini to attract passengers. This further worsens the noise situation. Nairobi City is prone to traffic congestion that tremendously slows down traffic speeds. This implies that PSVs take longer to reach their destinations and this increases the exposure time of PSV users to the high noise. The high noise may be subjecting PSV users to risks of suffering noise-induced impacts on their health and welfare.

Unfortunately, as compared to other environmental issues concerning soil and water, for instance, noise has not been given much attention in Kenya, even by scholars. In fact, Kenyan noise data is generally missing. This study sought to evaluate the extent and potential impacts of noise pollution inside PSVs in Nairobi, the capital city of Kenya. The results thereof would be used to probe the effectiveness of existing laws to control noise pollution and formulate possible technical and policy recommendations for noise control.

\section{Literature Review}

Noise pollution poses a wide range of risks to public health and welfare. Adverse effects of noise pollution include annoyance, speech interference, sleep disturbance and hearing loss. Recent studies have also associated noise with cardiovascular diseases such as hypertension and myocardial infarction [4, 26]. Traffic noise-related annoyance and sleep disturbance have become common problems throughout the world, with adverse effects on life quality and health [5, 27]. Another adverse effect of noise pollution that has been documented since the $16^{\text {th }}$ century, and is still a problem today, is occupation-related hearing loss. World records estimate that about US\$835 million was paid to workers between 1978 and 1987 in compensation for occupationrelated hearing loss. It has also been proven that noiseinduced sonic boom can result in physical damage of structures [6].
All over the world, noise levels have reached alarming levels, particularly in urban areas. The impact of noise pollution on communities is fast escalating especially in densely populated urban areas near very busy roads [7, 29, 32]. In Varanasi City, India, about $85 \%$ of the people are disturbed by traffic noise, $90 \%$ of whom consider noise as the main cause of headaches, hypertension, giddiness and lethargy $[8,25]$. In Canada, a nationwide survey indicates that half of Canadians are bothered by noise emanating outside their homes, mainly from road traffic [9]. In Denmark, a one (1) $\mathrm{dB}$ increase in noise levels results in a corresponding $1 \%$ decrease in house prices in main residential areas, indicating how reactive people there are to noise. In Rawalpindi and Islamabad, the environment management agency has raised concerns that the daily maximum and daily equivalent noise levels are significantly higher than the maximum permissible level [10]. In most towns/cities of Nigeria, noise emanating from traffic, industry, worship and commercial activities has been listed as an issue of key environmental concern [11, 12, 30]. In Uganda, has been noted as the main source of environmental pollution in the city of Kampala [13]. Additionally, in a study of noise pollution in restaurants of Morogoro town, Tanzania, [14] recorded between 61 and $64 \mathrm{dBA}$ of noise, which is way above the legislated maximum permissible limit of $55 \mathrm{dBA}$ and is associated with music in the restaurants, customer conversations as well as activity on adjacent streets. In sum, rapid urbanization, population growth, industrialization and associated socio-economic activities is fast escalating the level of noise pollution in most world cities and urban centers.

\section{Theory}

This study was based on various theoretical concepts of Acoustics. These include: sound characterisation, sound measurement, and human sound perception.

\subsection{Sound Characterization}

Sound is characterized in terms of three important parameters namely, sound pressure, sound power and sound intensity $[15,31]$. Sound pressure (denoted as $\Delta \mathrm{P}_{\mathrm{m}}$ ) is the maximum pressure differential, above and below the existing atmospheric pressure, which is responsible for sound propagation. This is based on the basic fact that sound results from a differential/disturbance in air pressures caused by the vibration of a sound source. The disturbance leads to formation of two pressure bands, the compression band, characterized by high pressures, and the rarefaction band of low pressures [16, 28, 31]. In the absence of sound pressure, no sound transmission occurs and the ear perceives no sound. Sound pressure is expressed as in equation 1 in which $U$ is the velocity of propagation of sound; $\rho$ is the mass density of air; $\omega$ is the angular frequency of the sound wave; $S_{m}$ is the maximum displacement and $\beta$ is the bulk modulus of elasticity of air [15]. 


$$
\Delta \mathrm{P}_{\mathrm{m}}=(\mathrm{U} \rho \omega) \mathrm{Sm} ; \mathrm{U}=\sqrt{ } \frac{\beta}{\rho}
$$

Like a compressed spring, the air that propagates a sound wave possesses potential energy, in its compressed state, and kinetic energy in the rarefaction state [16]. Neglecting any energy losses, the total energy content of a sound wave equals the sum of the potential and kinetic energy. Sound power $\left(\mathrm{P}_{\mathrm{w}}\right)$ is the rate of change of the energy (from potential to kinetic) with respect to time as given in equation 2 in which $\mathrm{A}$ is the cross-sectional area of propagation of the sound wave [15]. The rate of transmission of sound power per unit area of cross section (A) in the direction of travel of the sound is known as sound intensity (I). Sound intensity is commonly expressed in terms of the root mean square of the sound wave as shown in equation (3) [15].

$$
\begin{aligned}
P_{w} & =\frac{1}{2} \rho A v \omega^{2} S_{m}^{2} \\
I & =\frac{\Delta P_{r m s}^{2}}{\rho v}
\end{aligned}
$$

\subsection{Sound Measurement}

\subsubsection{The A-Weighted Decibel Scale}

Although sound is characterized in terms of pressure, power and intensity, noise measurements are never reported in the units thereof. This is because sound that a human ear can perceive comprises a wide range of pressures and intensities. Thus, to accommodate these wide variations, a logarithmic scale of zero to 140 units, known as decibels $(\mathrm{dB})$, is used [17, 34]. A decibel is defined by equation 4 in which: $\mathrm{x}$ is sound pressure/sound power/sound intensity; $\mathrm{y}$ refers to some arbitrary reference values which depend on the type of decibel being defined. The arbitrary reference values are $10^{-12} \mathrm{~W}$ for sound power; $2\left(10^{-5}\right) \mathrm{Pa}$ for intensity and $10^{-12}$ $\mathrm{W} / \mathrm{m}^{2}$ for sound pressure as shown in equations 5,6 and 7 [18].

$$
\begin{aligned}
& d B=10 \log \frac{x}{y} \\
& L_{w}=10 \log \frac{P_{w}}{10^{-12}} d B \\
& L_{I}=10 \log \frac{I}{10^{-12}} d B \\
& L_{p}=10 \log \frac{\Delta P_{r m s}^{2}}{\left(2 \times 10^{-5}\right)^{2}} d B
\end{aligned}
$$

Most sounds comprise of a wide range of frequencies which determine human ability to hear them. Humans readily hear sounds whose frequencies range from 1000 to $6000 \mathrm{~Hz}$. Sounds dominated by frequencies below $100 \mathrm{~Hz}$ and above $10,000 \mathrm{~Hz}$ are difficult to hear [19]. Sound measurements need to be done in a way that approximates human response by giving more weight to readily heard frequencies. In order to achieve this, several weighting scales have been developed for sound measurement. These include A, B, C, D and Eweighted scales [18]. The A-weighted scale has been conventionally adopted for environmental noise measurements due to its convenience and accuracy for most purposes. A-weighted sound level measurements are reported in units of dBA [15].

\subsubsection{Decibel Addition}

A given sound spectrum may consist of various decibel readings. These must be added up to give rise to an overall reading. The addition is performed logarithmically such that the overall/total decibel readings $\left(\mathrm{L}_{\mathrm{pT}}\right)$ for a sound spectrum comprising of sound pressures ranging from $\mathrm{L}_{\mathrm{p} 1}, \mathrm{~L}_{\mathrm{p} 2}, \ldots$ to $\mathrm{L}_{\mathrm{pn}}$ is given as shown in equation (8). Similarly, the total decibel readings corresponding to sound power level and sound intensity levels are computed as shown in equations 9 and 10 , respectively.

$$
\begin{gathered}
L_{p T}=10 \log \left(\sum_{i=1}^{i=n} \sqrt{10^{\frac{L_{p i}}{10}}}\right)^{2} \\
L_{w T}=10 \log \sum_{i=1}^{1=n} 10^{L_{w i} / 10} \\
L_{I T}=10 \log \sum_{i=1}^{1=n} 10^{L_{I i} / 10}
\end{gathered}
$$

The logarithmic additions described above have been summarized as shown in Table 1 [19];

Table 1. Decibel addition.

\begin{tabular}{ll}
\hline $\mathbf{L}_{\mathbf{1}}-\mathbf{L}_{\mathbf{2}}, \mathbf{d B}$ & Add to $\mathbf{L}_{\mathbf{1}}$ \\
\hline 0 or 1 & $3 \mathrm{~dB}$ \\
2 or 3 & $2 \mathrm{~dB}$ \\
$4-8$ & $1 \mathrm{~dB}$ \\
9 or more & $0 \mathrm{~dB}$ \\
\hline
\end{tabular}

\subsubsection{Miscellaneous Measures of Noise}

In practice, three miscellaneous measures of noise have evolved. This enables noise pollution to be regarded in three dimensions namely, community noise, industrial noise and airport noise. Industrial noise and airport noise refer to noise emanating from industrial processes and airport operations respectively [20]. Community noise (also known as environmental noise) refers to noise emanating from common day-to-day human activities such as transportation, recreation, entertainment, worship, business, animal rearing, construction and domestic activities. Most often, noise from a combination of these sources add up to give rise to overall community/environmental noise and it may not be easy to discriminate and quantify the individual point sources. Thus, as a measure of noise, community/environmental noise seeks to conceptualize the noise environment in which human beings are exposed in their day-to-day life.

Various measures have been developed for quantifying community noise. These include: the statistical measure $\left(\mathrm{L}_{\mathrm{N}}\right)$, continuous equivalent sound level $\left(\mathrm{L}_{\mathrm{eq}}\right)$ day-night average sound level $\left(\mathrm{L}_{\mathrm{dn}}\right)$ and noise pollution level $\left(\mathrm{L}_{\mathrm{NP}}\right)$. Out of these measures, the continuous equivalent sound level is the most widely used for community noise assessment. $\mathrm{L}_{\mathrm{eq}}$ is preferred for describing sound levels which vary over time to result in a single decibel reading. It accounts for the total sound energy involved over the given period of time and gives an 
A-weighted average equivalent for the period. $\mathrm{L}_{\mathrm{eq}}$ is expressed as shown in equation 11 in which: $\mathrm{p}_{0}$ is the reference pressure level (typically taken as $20 \mu \mathrm{Pa}$ ); $\mathrm{p}_{\mathrm{A}}$ is the acquired sound pressure; $t_{1}$ and $t_{2}$ are the start time and end time for measurement, respectively [15].

$$
L_{e q}=10 \log \left[\frac{1}{t_{1}-t_{2}} \int_{t_{1}}^{t_{2}} \frac{p_{A}^{2}}{p_{0}^{2}} d t\right]
$$

The statistical measure refers to a sound level that is either equaled or exceeded a given percent of the time, based on a probability distribution analysis. For instance, $\mathrm{L}_{90}, \mathrm{~L}_{20}$ and $\mathrm{L}_{10}$ refer to noise levels that are equaled/exceeded $90 \%, 20 \%$ and $10 \%$ of the time, respectively. The day-night average sound level is the equivalent sound level over a 24 hour period with an additional $10 \mathrm{~dB}$ (A) during the night $(10.00$ P.M. to 7.00 A.M.). Community noise levels can also be described in terms of another measure known as the community noise equivalent level (CNEL). CNEL is related to $\mathrm{L}_{\mathrm{DN}}$ except that an additional $5 \mathrm{~dB}(\mathrm{~A})$ is imposed between 7.00 P.M. and 10.00 P.M. and $10 \mathrm{~dB}(\mathrm{~A})$ is added between 10.00 P.M. and 7.00 A.M. Noise pollution level is the equivalent sound level with a probability of exceedance of $0.5 \%[8,15]$.

\subsubsection{The Sound Level Meter}

The instrument used to measure noise is the sound level meter. The meter should be located at a reasonable distance from the sound source to avoid obstruction [21]. The sound level meter is first calibrated by a calibrator. When attached to the sound level meter, the calibrator produces a reference sound that calibrates the meter. Basically, a sound level meter consists of four parts namely, a microphone, sound amplifiers, weighting network and a display which shows readings in decibels $[22,33]$. The sound pressure of an incoming sound is received by the microphone where the pressure pattern of the sound is mimicked by a pressure transducer (such as a diaphragm) and the signal is converted to a small current of electricity. The resulting electrical signal if amplified by the amplifiers and an equivalent reading shown on the screen [19].

It is important to note that the sound pressure received by the meter is not the same as that which the ear perceives. As a result, a weighting network (A, B, C, D and E) - simply an electrical circuitry - is incorporated in the meter to help approximate human response and give a reading as close to it as possible [23]. The work of the weighting network circuitry is to electronically subtract the actual sound pressure level, at a particular frequency, received at the microphone with respect to the network upon which the meter is set [19]. A sample plot of weighting networks for scale A, B and C is shown in the Figure 1. The difference between the actual pressure level and a given frequency-dependent value, from the weighting network plot, is displayed as the sound level reading. The units of this reading depend on the scale used thus it may be reported as $\mathrm{dBA}, \mathrm{dBB}$ or $\mathrm{dBC}$ for scales $\mathrm{A}, \mathrm{B}$ and $\mathrm{C}$, respectively. While the A-network is recommended for most community noise measurements, the D network is best suited for approximating human response to airport noise [15].

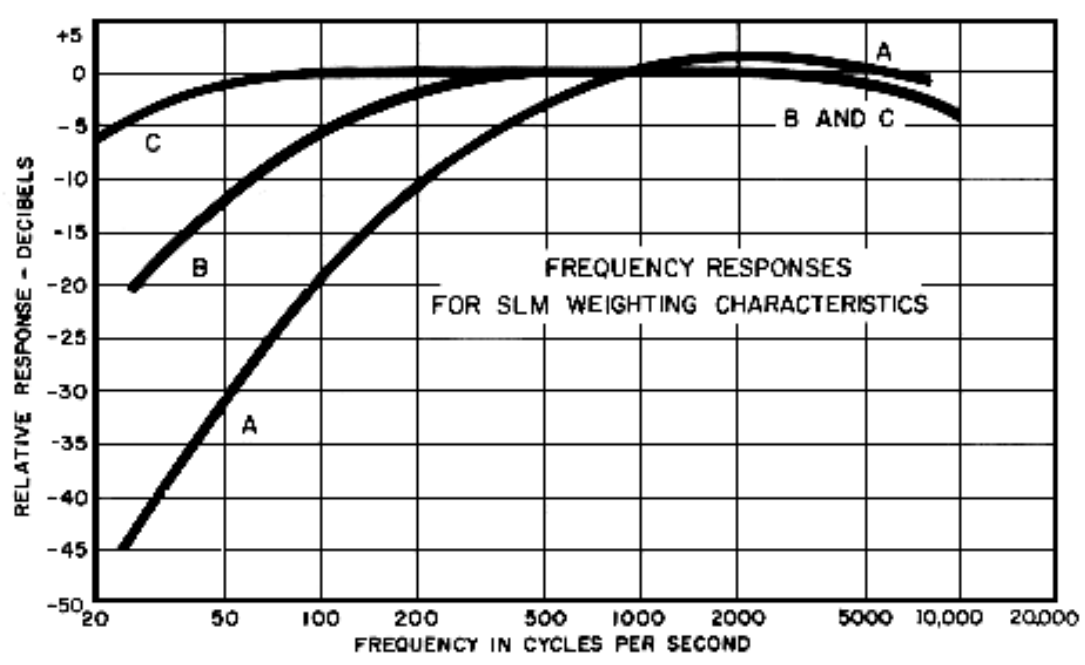

Adapted from: (http://www.sfu.ca/sonicstudio/handbook/Graphics/Sound_Level_Meter.gif)

Figure 1. Plot of weighting networks.

\section{Materials and Methods}

The study area was divided into four geographical routes, namely, Nairobi CBD-Nairobi East, Nairobi CBD-Nairobi West, Nairobi CBD-Nairobi North and Nairobi CBD-Nairobi South as shown in Figure 2. On each route, fifteen (15) PSVs were selected by simple random sampling for analysis. These comprised buses, mini-buses and 14-seater vans which are the commonest means of public road transport in Kenya. Posing as passengers in every PSV, continuous equivalent sound measurements (LAeq) were taken using a digital integrating sound level meter (SLM). The SLM used (SVANTEK 971) is a Type 1 SLM which gives measurements to the IEC 61672-1:2002 standards. The meter 
is also capable of computing LAeq levels directly thus minimizing computations and enhancing the accuracy of resulting measurements. In order to enhance the integrity of measured noise levels, PSVs were assessed for noise pollution anonymously, without the consent of their crew. This was due to fear that some may deliberately regulate, particularly, the level of music playing in their vehicles, if they knew they were under study.

Prior to its use, the SLM was calibrated, as per the manufacturer's manual, using a calibrator model SV34 and set to the "fast" and "A-Weighting network" modes. Measurements were taken with the SLM placed at a convenient sitting position. In each PSV, measurements were taken at five minutes intervals for the entire duration of travel, which ranged from 15 minutes to one hour. An average of the measurements taken was then computed and taken as the average LAeq for each PSV. The fifteen measurements taken in every route were further averaged to obtain a representative value for each route.

The measured LAeq were compared with recommended (legislated) limits and the extent of pollution quantified by the percentage deviation from (above) the limits [1]. Additionally, in order to assess the potential effects of this noise on PSV users, the measured LAeq were compared with the World Health Organization and the Environmental Protection Agency's guidelines recommended to protect public health and welfare from adverse impacts of noise. The degree of deviation from the protective guidelines was used to determine the level of risk posed to victims by noise inside PSVs.

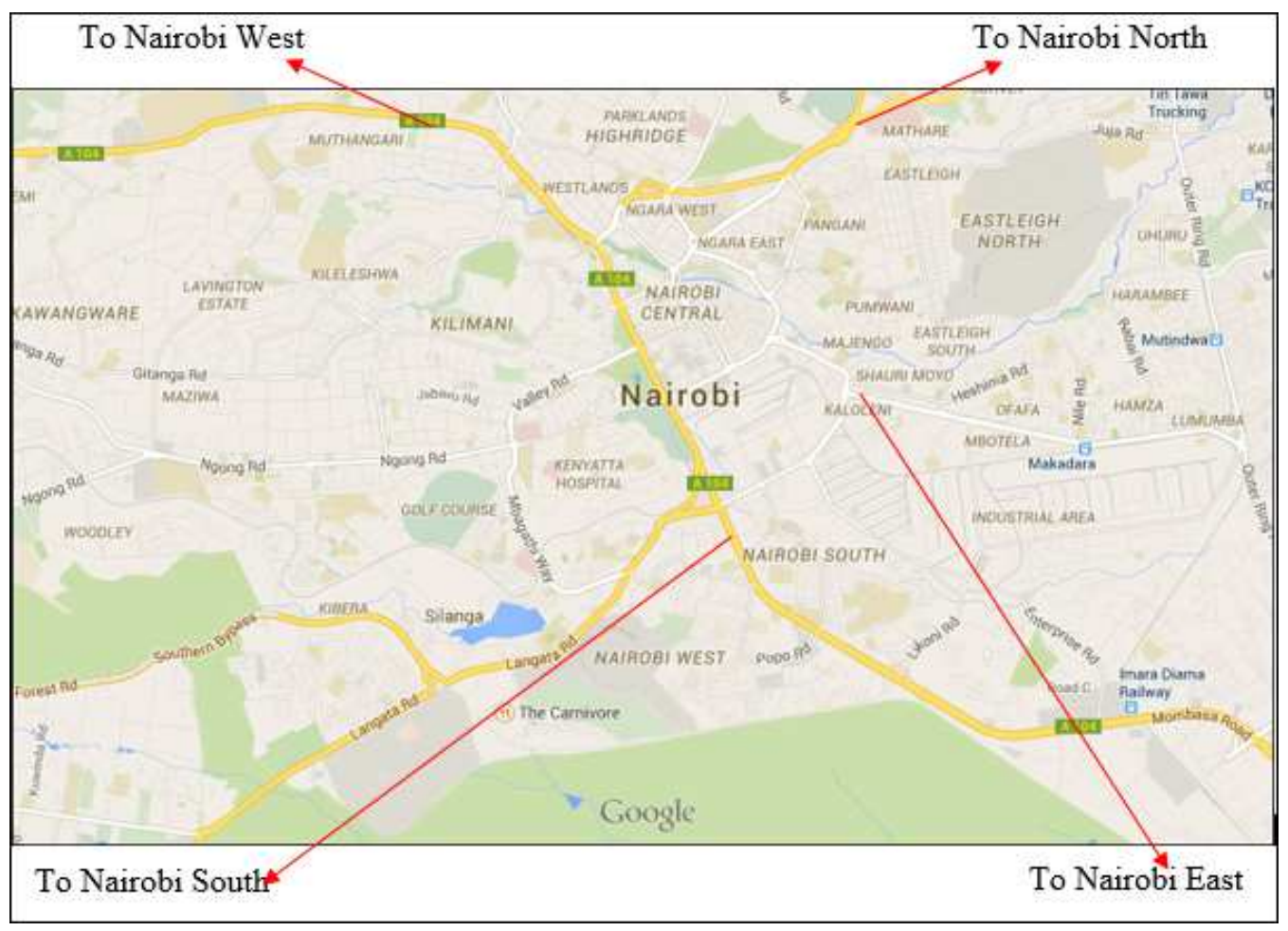

(Source: Google Earth)

Figure 2. A map showing the main PSV routes in Nairobi City.

\section{Results and Discussion}

\subsection{The Extent of Noise Pollution inside PSVS}

The extent of noise pollution inside PSVs in Nairobi City was established as follows.

\subsubsection{Nairobi CBD-Nairobi North PSVS}

Figure 3 shows the noise levels observed among PSVs operating between Nairobi CBD and various destinations north of the CBD such as Githurai 45, Kahawa, Kenyatta University (KU), Kasarani, Lucky Summer, Mwiki and Thika (46;237), among others. The main road serving this route is the Nairobi-Thika Superhighway which connects to various feeder roads. On average, the noise level inside these PSVs was found to be $92.2 \pm 9.4 \mathrm{~dB}$ (A). Two Githurai 45 buses exhibited the highest noise level in this route, 108.8 and $108.2 \mathrm{~dB}(\mathrm{~A})$, respectively. These were followed closely by a Thika-bound minibus (Route 237) in which $107.3 \mathrm{~dB}$ (A) was recorded. Other significantly high noise levels were measured inside a KU 45 Minibus (98.8 dB A) and a Mwiki 17 bus (96.6 dB A). In contrast, a 14-seater KU-bound Matatu and a Thika 237 minibus exhibited the lowest noise levels in this route: $76.6 \mathrm{~dB}(\mathrm{~A})$ and $84.4 \mathrm{~dB}(\mathrm{~A})$, respectively.

Going by these results, noise levels in all Nairobi North PSVs are higher than the maximum permissible level of 60 dBA. Even the lowest noise levels recorded in some PSVs in this route are still significantly higher than the permissible limit, with $54 \%$ average rate of non-compliance with the Noise Act. 
This study further revealed that the high noise level in northern Nairobi PSVs is a direct result of loud music/radio played inside the vehicles using sound amplifying equipment. Touting (banging of the vehicle bodies by touts; whistling; shouting; and uncontrolled hooting) were seen to be another major source of noise, especially among Githurai 45 buses and minibuses plying the Nairobi CBD-Nairobi North route.

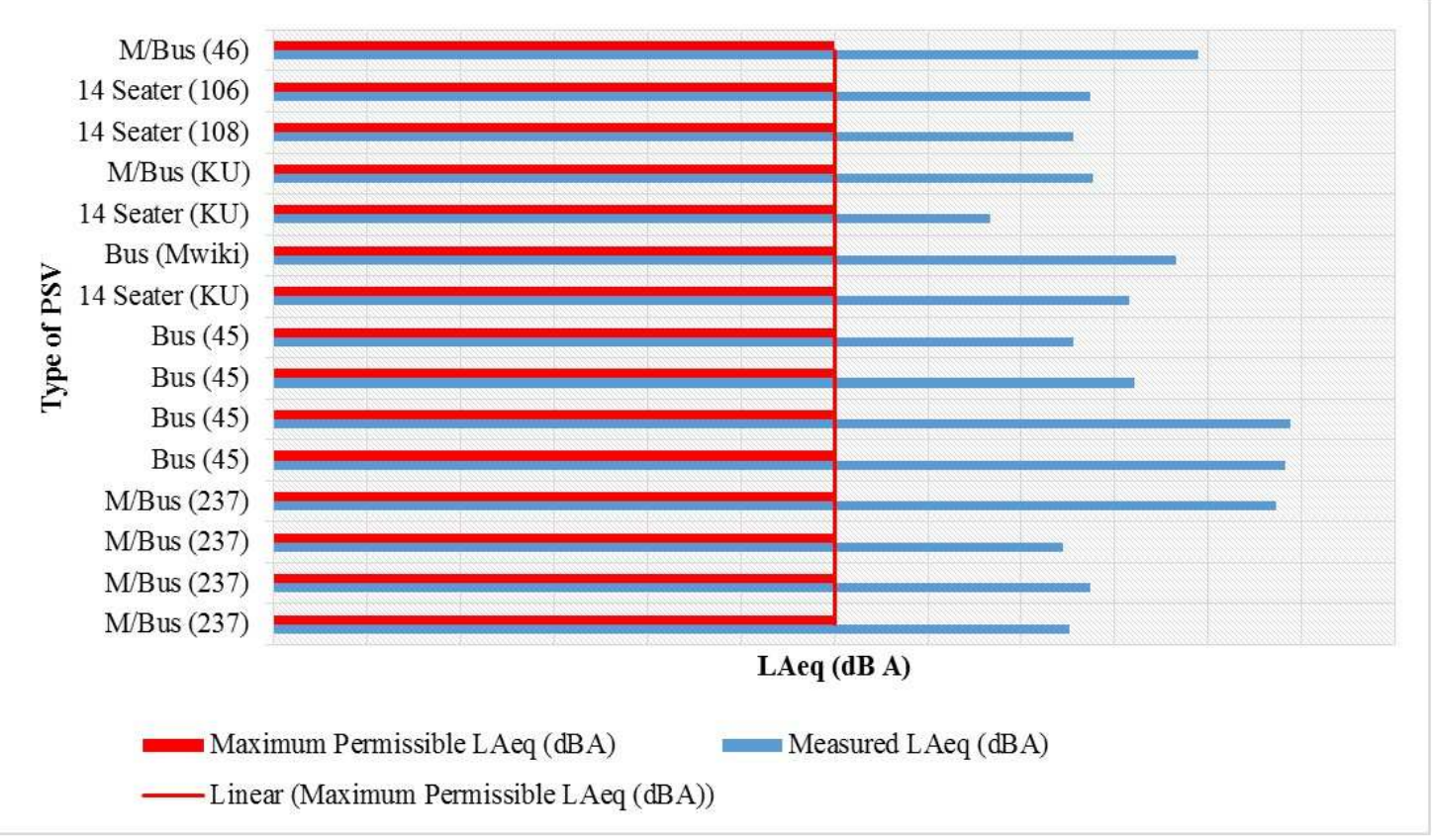

Figure 3. Noise inside Nairobi CBD-Nairobi North route PSVs.

\subsubsection{Nairobi CBD-Nairobi South PSVS}

The extent of noise pollution observed inside Matatus operating between Nairobi CBD and various destinations south of the city (such as: South B, South C, Hazina, Langata, Ngong, Karen, Kibera, Kiserian, Ongata Rongai and Bomas, among others) is presented in Figure 4. The main roads serving the southern area are Langata Road and Ngong Road and their associated feeder roads. Like in the northern region, all Matatus sampled in the south exceeded the maximum permissible noise level of $60 \mathrm{~dB}$ (A). On average, a noise level of $83.1 \pm 6.3 \mathrm{~dB}(\mathrm{~A})$ was recorded in these Matatus. This represents a $39 \%$ extent of non-compliance with the Noise Act. A South B (Route 11B) minibus and Ngong Minibus exhibited the highest level of noise ( $96.5 \mathrm{dBA})$ in this route. This signifies a high of $61 \%$ non-compliance with the Noise Act. The high noise levels are directly attributable to loud music played in the Matatus using sound amplifying equipment. To a little extent, touting could also be pointed out as a noise source in Nairobi South Route Matatus, though not as extensive as witnessed in the north.

In contrast, the least noise level recorded in this region was 75.2 dBA. This was observed in a mini bus plying Nairobi CBD-South B (route 11B). Unlike the matatus that exhibited the highest noise levels, this minibus played radio without the aid of sound amplifying equipment. Thus, the $75.2 \mathrm{dBA}$ noise level could be attributed to other factors observed in the matatus such as: touting, normal vehicle engine sounds, human (passenger) sounds and possible sounds from the outside environment. This shows that the use of sound- amplifying equipment inside PSVs greatly increases the noise pollution situation therein. Other matatus, in this region, that exhibited relatively lower noise levels include: an 11B bus (76.6 dB A); an 11B Minibus (77.7 dB A); and an 11B 14-seater (78.1 dB A).

\subsubsection{Nairobi CBD-Nairobi East PSVS}

The Nairobi CBD-Nairobi East route serves the vast eastern Nairobi region (popularly known as East-lands). The main roads traversing this region include: Jogoo Road, Mombasa Road and Juja Road and their associated feeder roads. Major estates in these region include: Buruburu, Doonholm, Kariobangi, Umoja, Makadara, Pipeline, Kayole and City-Kabanas, among others. East-lands' route matatus recorded an average internal noise level of $81.2 \pm 7.7 \mathrm{~dB}(\mathrm{~A})$, signifying $35 \%$ average non-compliance with the Noise Act (Figure 5). Some three minibuses exhibited the highest noise levels in this region, one plying Buruburu Route 58 (94.6 dB A); the second plying Kayole Route (94.6 dB A) and another Buruburu Route 58 minibus $(91.2 \mathrm{~dB}$ A). Like in the north and south, the high noise is a direct result of amplified music in the vehicles. This is in contrast to matatus without amplified music such as Double M (Route 33/34) which exhibited the lowest noise level of $68.8 \mathrm{~dB}$ (A). This represents a low of $15 \%$ non-compliance with the Noise Act and is attributed mainly to normal vehicular traffic sounds such as engine sounds, human sounds and possible sounds from the outside environment. While inside these less noisy matatus, it was observed that, unlike inside the noisy ones, speech/telephone communication could go on uninterrupted. 


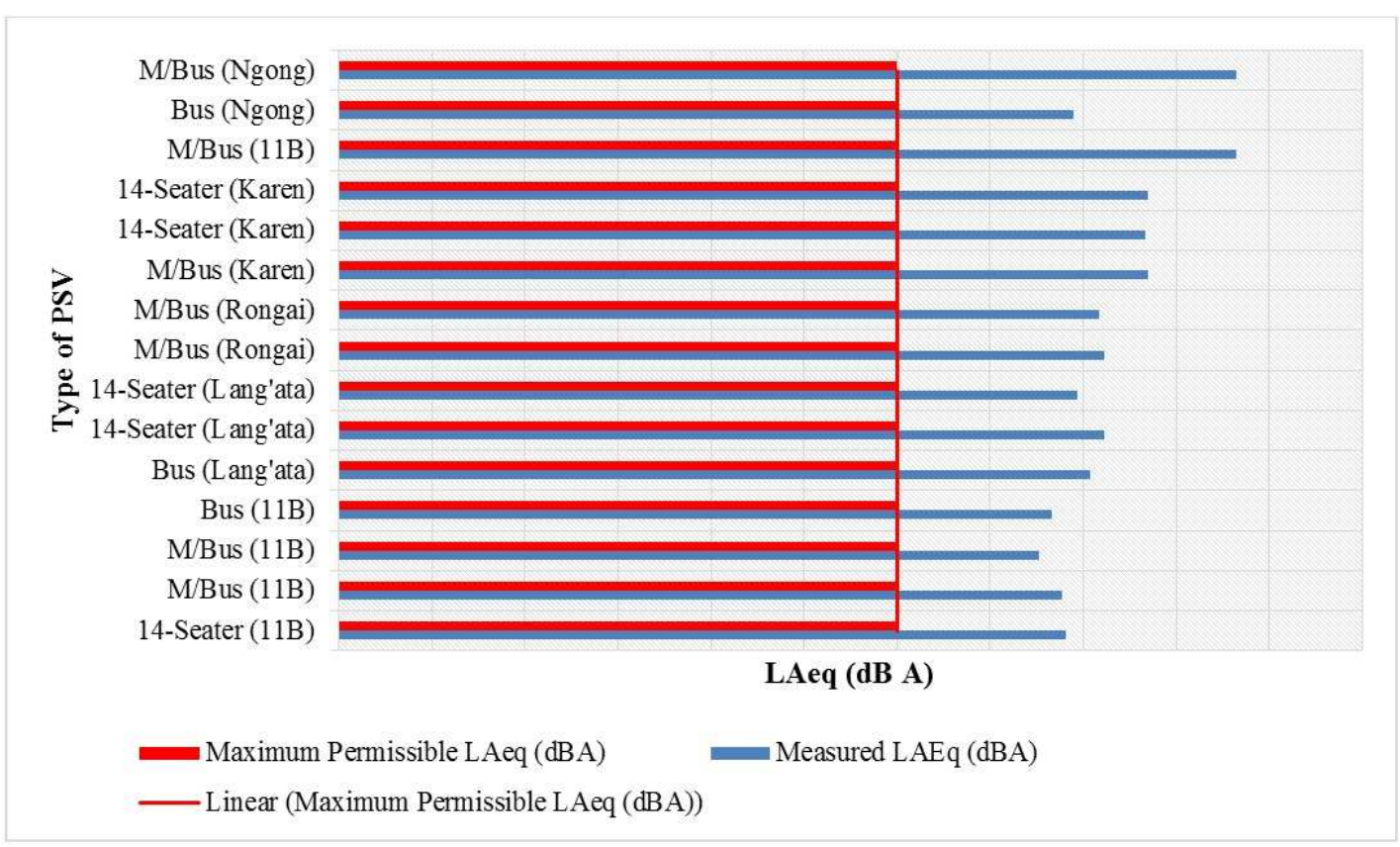

Figure 4. Noise inside Nairobi CBD-Nairobi South route PSVS.

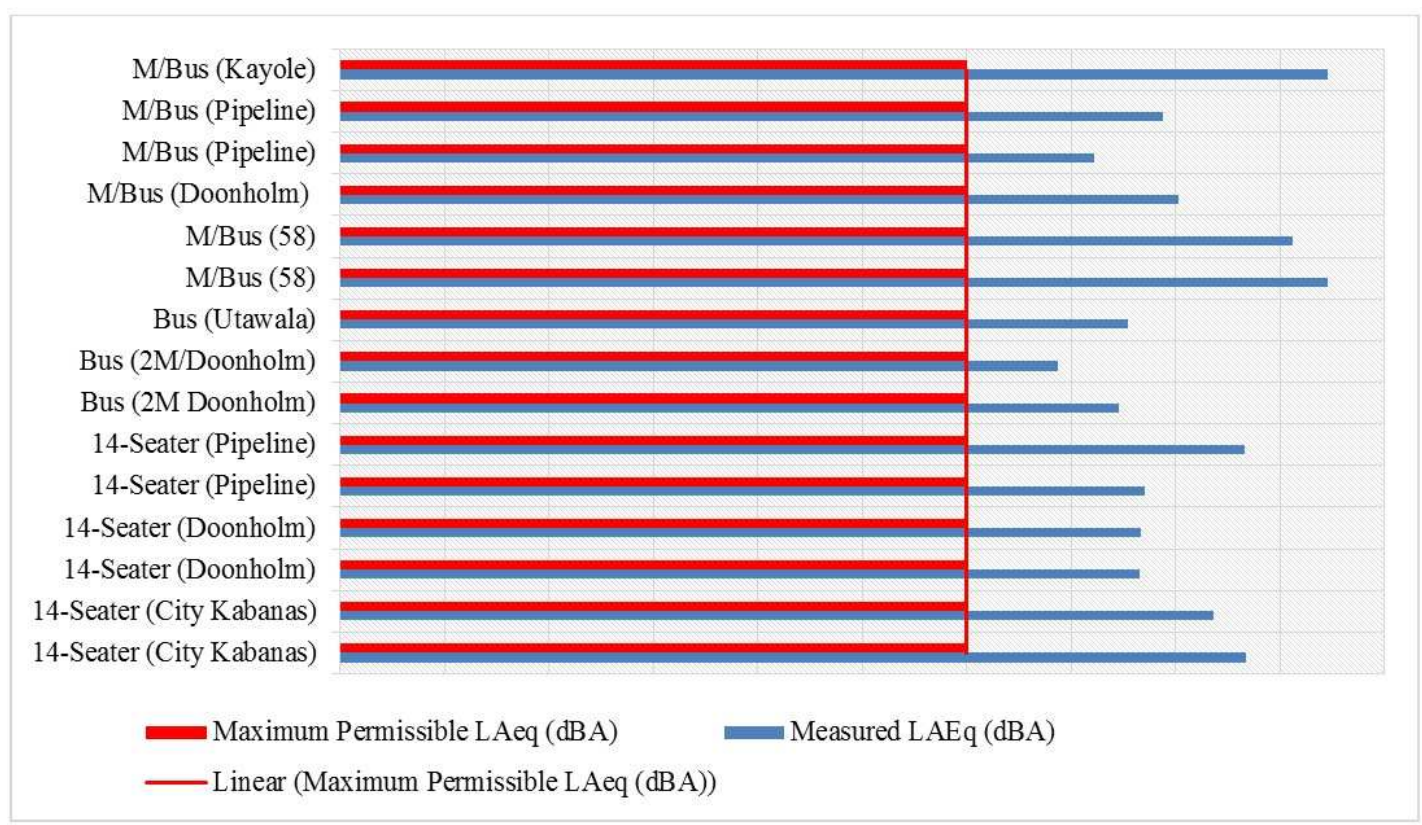

Figure 5. Noise inside Nairobi CBD-Nairobi East route PSVs.

\subsubsection{Nairobi CBD-Nairobi West PSVS}

The Western region of Nairobi includes areas such as Westlands, Kabete, Uthiru, Kinoo, Parklands, Mountain View, Satellite and Kikuyu, among others. The main road serving this area is Waiyaki Way and its associated feeder roads. The average noise level measured inside matatus in this region was $88.7 \pm 9.6 \mathrm{~dB}(\mathrm{~A})$, representing $48 \%$ non-compliance with the Noise Act (Figure 6). Two minibuses (Star Bus) plying this route exhibited the highest noise level of 107.2 and 104.1 $\mathrm{dB}(\mathrm{A})$, respectively. These were followed closely by a third minibus in which $98.9 \mathrm{~dB}(\mathrm{~A})$ was recorded. Like the other regions, it was observed that the high noise levels in these matatus is a direct result of the use of sound-amplifying equipment to play extremely loud music in the vehicles. In fact, the loud music overpowered all the other noise sources such as engine and human sounds and it was practically impossible to make speech/telephone communication in the vehicles. On the other hand, some PSVs in the Western region exhibited relatively low noise levels. These were buses operating in the Nairobi-Kabete route and their observed noise levels varied from 75-77 dB (A). They played either no music at all or very low music/radio without using 
sound-amplifying devices. As opposed to their counterparts with loud noise, it was possible to communicate easily and make calls in these matatus without shouting.

\subsubsection{Comparison of Various Routes}

Figure 7 compares the mean noise levels measured in PSVs plying routes in the four regions of Nairobi City. The results show that the Nairobi CBD-Nairobi North PSVs are the noisiest, with an average noise level of 92.2 $\pm 9.4 \mathrm{dBA}$. The second noisiest matatus are those in the Nairobi-Nairobi West route at $88.7 \pm 9.6 \mathrm{dBA}$. These are in turn followed by matatus in the southern region which recorded an average of $83.1 \pm 6.3 \mathrm{dBA}$. The lowest noise levels were observed in the eastern region whose matatus average $81.2 \pm 7.7 \mathrm{dBA}$. This implies that, in terms of compliance to the Noise Act, the most non-compliant route is Nairobi North at $54 \%$ followed by: Nairobi West (48\%); Nairobi South (38\%); and Nairobi East (35\%). As shown in Table 2 and Table 3, these deviations from legislated noise limits are statistically significant, as per one-sample t-tests conducted at 95 and $99 \%$ confidence intervals.

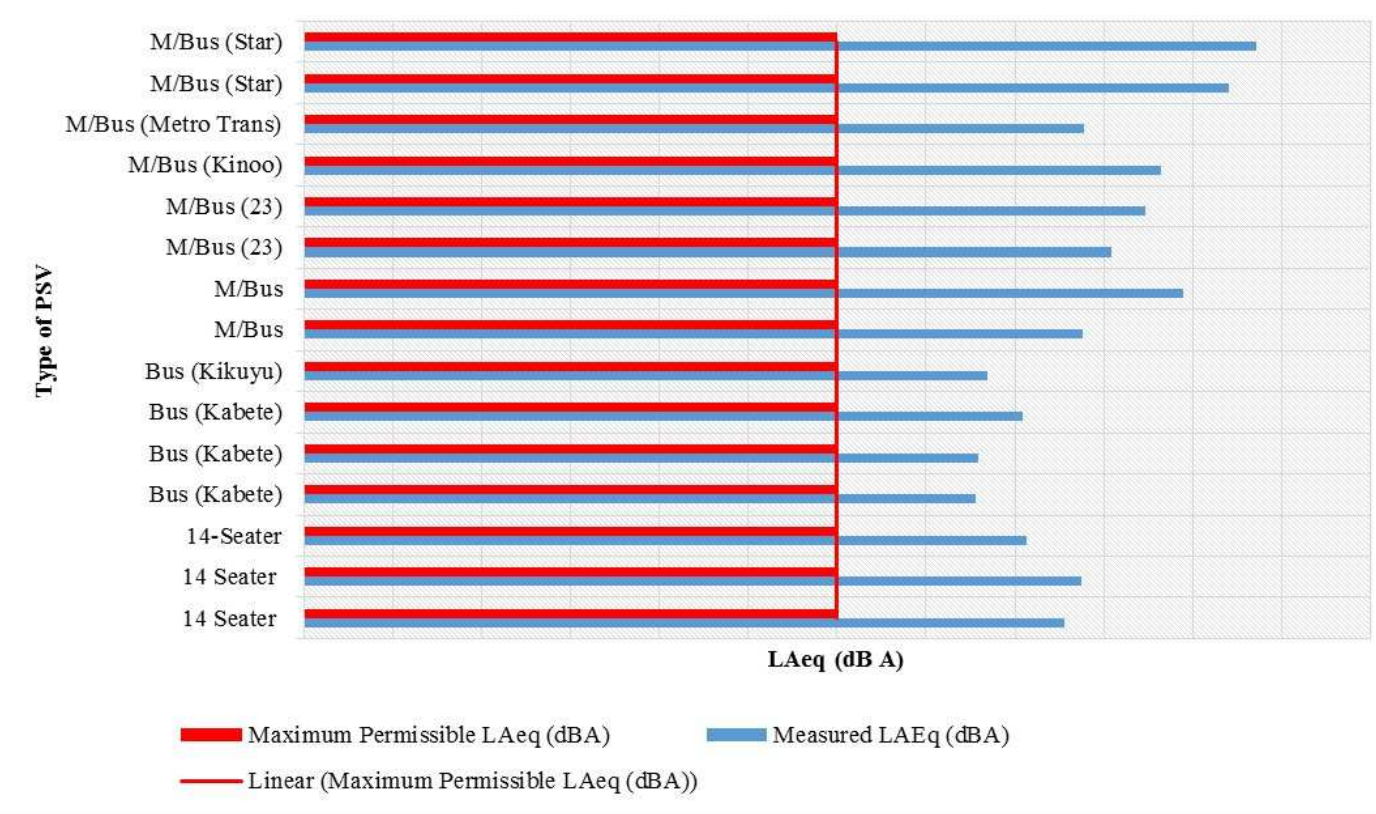

Figure 6. Noise inside Nairobi CBD-Nairobi West route PSVS.

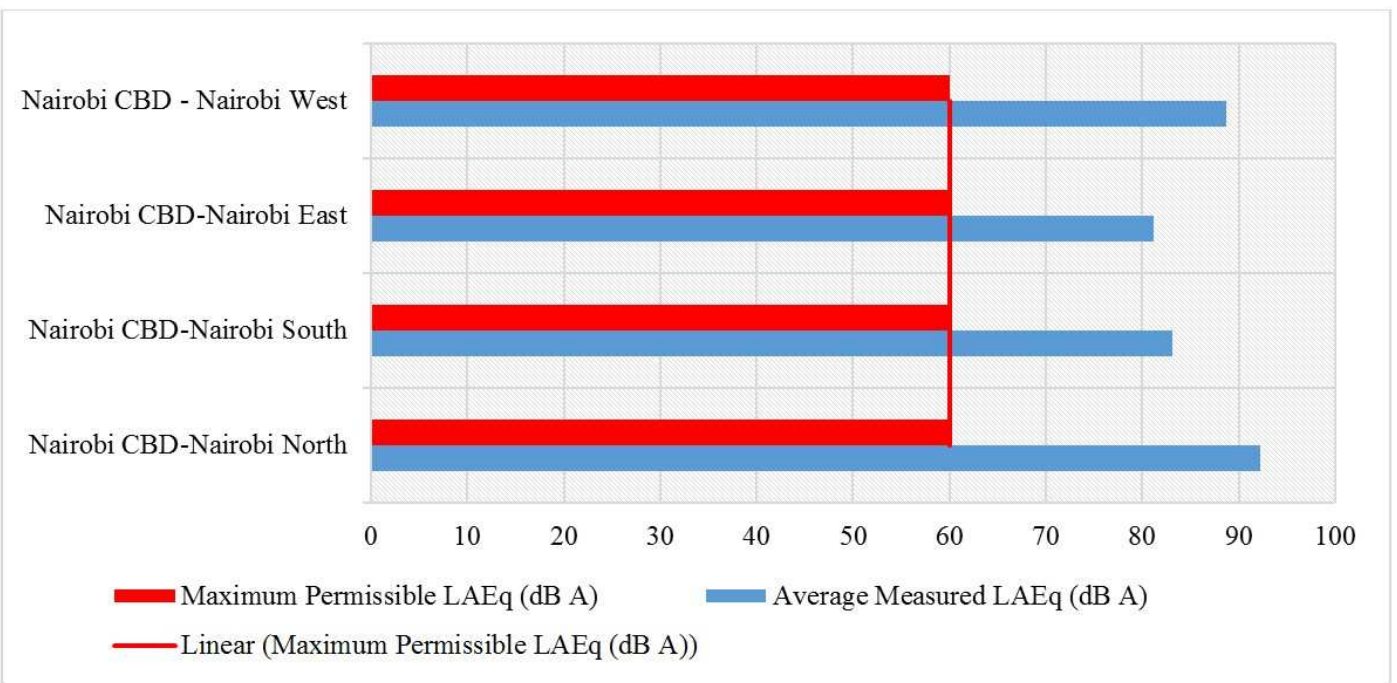

Figure 7. Comparison of noise pollution levels for different PSV routes in Nairobi City.

Table 2. One-sample t-test at $95 \%$ confidence interval (CI).

\begin{tabular}{|c|c|c|c|c|c|c|}
\hline & $\mathbf{t}$ & df & Sig. (2-tailed) & $\begin{array}{l}\text { Mean } \\
\text { Difference }\end{array}$ & Lower & Upper \\
\hline PSV Measured Values & 10.395 & 3 & .000 & 26.300 & 18.25 & 34.35 \\
\hline
\end{tabular}


Table 3. One-sample t-test at $99 \%$ CI.

\begin{tabular}{lllllll}
\hline & t & df & Sig. (2-tailed) & $\begin{array}{l}\text { Mean } \\
\text { Difference }\end{array}$ & 99\% Confidence Interval of the Difference & Lower \\
\hline PSV Measured Values & 10.395 & 3 & .002 & 26.300 & 11.52 & Upper \\
\hline
\end{tabular}

\subsection{Causes of Noise Pollution inside PSVS}

Regarding the causes of noise inside PSVs, this study further revealed that the high noise level in northern Nairobi PSVs is a direct result of loud music/radio played inside the vehicles using sound amplifying equipment. This renders communication endeavors (speech or telephone communication) virtually impossible while travelling in the PSVs. In addition, touting (banging of the vehicle bodies by touts; whistling; shouting; uncontrolled and uncontrolled hooting) was also seen to be another major source of noise, especially among Githurai 45 buses and minibuses plying the Nairobi CBD-Nairobi North route. Other than communication interference, the high noise levels in PSVs put passengers at risk of suffering noise-induced hearing loss, physiological and psychological defects [24].

\subsection{Potential Impacts of Noise Pollution}

As already indicated, $100 \%$ of PSVs and bus stations in Nairobi city violate the legislated noise regulations. This poses a wide range of risks to public health and welfare, particularly among passengers. Also, most of the PSV roads and bus stations are located in/near residential estates, offices, hospitals or schools. It is also important to note that Nairobi faces a serious problem of traffic congestion thereby increasing the duration for which passengers, pedestrians and near-road users/dwellers are exposed to traffic noise. Considering the average noise levels established in this study, an average Nairobi resident is exposed to $79.7 \pm 6.0 \mathrm{~dB}$ (A) of noise while awaiting to board a PSV in a bus station; followed by $86.3 \pm 9.6 \mathrm{~dB}$ (A) while travelling in a matatu and as the PSV maneuvers through slow traffic to and from work, daily.

To predict the possible noise impacts, an overall average value was computed of all the measured noise levels in this study. The value was found to be $83 \mathrm{~dB}$ (A). To predict possible effects of noise, Table 4, compares this overall average noise level with various international standards recommended to protect public health and welfare with an adequate margin of safety $[24,25,26]$. From the table, it is evident that Nairobi faces a high risk of various adverse noise effects. These include: NIHL, physiological effects (e.g. hypertension and cardiovascular disease), psychological effects, annoyance and behavioral effects. This is because the overall average value $(83 \mathrm{~dB} A)$ exceeds the maximum permissible levels of $70 ; 65-70 ; 70$; and $80 \mathrm{~dB}$ (A), respectively. In addition, the study established that there is a very high risk of other effects of noise such as speech interference, sleep disturbance, and activity interference whose recommended limits are $35-55 ; 30$; and 45-55, respectively.

Table 4. Potential impacts of noise pollution inside PSVs in Nairobi City.

\begin{tabular}{lllll}
\hline Effect of noise & $\begin{array}{l}\text { Protective noise limit (LAEq, } \\
\mathbf{2 4 h}, \mathbf{d B} \text { A) }\end{array}$ & $\begin{array}{l}\text { Duration of exposure } \\
\text { (Years) }\end{array}$ & $\begin{array}{l}\text { Measured noise level } \\
\text { (LAEq, 24h, dB A) }\end{array}$ & $\begin{array}{l}\text { Inference (level of } \\
\text { risk) }\end{array}$ \\
\hline $\begin{array}{l}\text { Noise Induced Hearing Loss (NIHL) } \\
\text { Physiological Effects (Hypertension, }\end{array}$ & 70 & $20-40$ & 83 & High Risk \\
Cardiovascular Disease, etc.) & $65-70$ & $5-30$ & 83 & High Risk \\
Psychological/Mental Illness/Stress & 70 & ST-LT & 83 & High Risk \\
Speech Interference (Indoors) & 35 & ST & 83 & Very High Risk \\
Speech Interference (Outdoors) & 55 & ST & 83 & Very High Risk \\
Sleep Disturbance & 30 & ST & 83 & Very High Risk \\
Activity Interference & $45-55$ & ST & 83 & Very High Risk \\
Annoyance/Social/Behavioural Effect & 80 & ST & 83 & High Risk \\
\hline
\end{tabular}

Key: ST - Short-term (Instant) Effects LT - Long-term Effects

\section{Conclusions and Recommendations}

Kenyans are exposed to dangerously high noise inside PSVs. An average noise level of $86.3 \pm 9.5 \mathrm{~dB}$ (A) was recorded inside PSVs. These levels are way above the maximum permissible limit of $60 \mathrm{~dB}$ (A) and are mainly associated with the use of sound amplifying equipment to play loud music/radio inside PSVs. The high noise pollution level raises two main concerns. Firstly, there is inadequate enforcement of environmental laws in Nairobi City. Secondly, existing laws for noise control are inadequate to effectively control noise.

This calls on law-enforcement agencies to intensify environmental law enforcement in the city. In addition, the laws governing noise pollution in the country need to be reconsidered to ascertain not only their ability to control noise pollution, but also whether they are attainable to law keepers. It is also imperative that more attention is given to the study and monitoring of noise pollution in Nairobi City. Additionally, other mechanisms of creating public awareness of noise pollution should be explored to help reduce irresponsible generation of and exposure to excessive noise 
among members of the public as is the case with PSV crew in Nairobi.

\section{Acknowledgement}

Sincere gratitude is expressed to the Division of Research, Production and Extension, Jomo Kenyatta University of Agriculture and Technology, Nairobi Kenya, for funding the study. The authors also thank the Environmental management agencies in Kenya (NEMA and DOSHS) for their support and advice; and the Nairobi County Environment Office, for approving and facilitating access to the study area.

\section{Appendices}

Measured Noise Levels

\begin{tabular}{|c|c|c|c|c|}
\hline \multicolumn{5}{|c|}{ Nairobi-Nairobi North Route PSVs } \\
\hline $\begin{array}{l}\mathbf{S} / \\
\mathbf{N}\end{array}$ & Type & $\begin{array}{l}\text { LAEq } \\
\text { (dBA) }\end{array}$ & $\begin{array}{l}\text { L90 } \\
\text { (dBA) }\end{array}$ & Remarks \\
\hline 1 & M/Bus (237) & 85.2 & 78.8 & Radio \\
\hline 2 & $\mathrm{M} / \mathrm{Bus}(237)$ & 87.4 & 80.1 & Music \\
\hline 3 & M/Bus (237) & 84.4 & 78.9 & Music \\
\hline 4 & M/Bus (237) & 107.3 & 85.3 & Music/Touting \\
\hline 5 & Bus (45) & 108.2 & 85.7 & Music/Touting \\
\hline 6 & Bus (45) & 108.8 & 79.5 & Music/Touting \\
\hline 7 & Bus (45) & 92.1 & 86.2 & Music/Touting \\
\hline 8 & Bus (45) & 85.6 & 76.2 & $\begin{array}{l}\text { Radio/Old } \\
\text { Vehicle }\end{array}$ \\
\hline 9 & 14 Seater $(K U)$ & 91.6 & 84.6 & $\begin{array}{l}\text { Music/Old } \\
\text { Vehicle }\end{array}$ \\
\hline 10 & Bus (Mwiki) & 96.6 & 87.2 & Music \\
\hline 11 & 14 Seater $(K U)$ & 76.6 & 73.1 & Low Radio \\
\hline 12 & $\mathrm{M} / \mathrm{Bus}(\mathrm{KU})$ & 87.6 & 81.3 & Music \\
\hline 13 & 14 Seater (108) & 85.6 & 79.9 & No Music/Old \\
\hline 14 & 14 Seater $(106)$ & 87.4 & 82.1 & Music \\
\hline 15 & M/Bus (46) & 98.9 & 94.6 & Music \\
\hline \multicolumn{5}{|c|}{ Nairobi-Nairobi West Route PSVs } \\
\hline $\begin{array}{l}\mathrm{S} / \\
\mathrm{N}\end{array}$ & Type & $\begin{array}{l}\text { LAEq } \\
\text { (dBA) }\end{array}$ & $\begin{array}{l}\text { L90 } \\
(\mathrm{dBA})\end{array}$ & Remarks \\
\hline 1 & 14 Seater & 85.6 & 79.9 & \\
\hline 2 & 14 Seater & 87.4 & 82.1 & \\
\hline 3 & 14-Seater & 81.3 & 76.2 & Music/Old \\
\hline 4 & Bus (Kabete) & 75.6 & 67.4 & $\begin{array}{l}\text { Low } \\
\text { Music/Old }\end{array}$ \\
\hline 5 & Bus (Kabete) & 75.9 & 69.9 & No Music \\
\hline 6 & Bus (Kabete) & 80.9 & 77.8 & Music \\
\hline 7 & Bus (Kikuyu) & 76.9 & 70.9 & $\begin{array}{l}\text { Low } \\
\text { Music/Old }\end{array}$ \\
\hline 8 & $\mathrm{M} / \mathrm{Bus}$ & 87.6 & 81.3 & \\
\hline 9 & M/Bus & 98.9 & 94.6 & Music \\
\hline 10 & M/Bus (23) & 90.9 & 84.7 & \\
\hline 11 & M/Bus (23) & 94.6 & 85.1 & \\
\hline 12 & M/Bus (Kinoo) & 96.4 & 90.1 & \\
\hline 13 & M/Bus (Metro Trans) & 87.7 & 76.2 & Music \\
\hline 14 & M/Bus (Star) & 104.1 & 79.5 & Music/Touting \\
\hline 15 & M/Bus (Star) & 107.2 & 85.6 & Music/Touting \\
\hline \multicolumn{5}{|c|}{ Nairobi-Nairobi East Route PSVs } \\
\hline $\begin{array}{l}\mathrm{S} / \\
\mathrm{N}\end{array}$ & Type & $\begin{array}{l}\text { LAEq } \\
(\mathrm{dBA})\end{array}$ & $\begin{array}{l}\text { L90 } \\
\text { (dBA) }\end{array}$ & Remarks \\
\hline 1 & 14-Seater (City Kabanas) & 86.7 & 81.3 & Music \\
\hline
\end{tabular}

\begin{tabular}{|c|c|c|c|c|}
\hline \multicolumn{5}{|c|}{ Nairobi-Nairobi North Route PSVs } \\
\hline $\begin{array}{l}\text { S/ } \\
\mathbf{N}\end{array}$ & Type & $\begin{array}{l}\text { LAEq } \\
\text { (dBA) }\end{array}$ & $\begin{array}{l}\text { L90 } \\
\text { (dBA) }\end{array}$ & Remarks \\
\hline 2 & 14-Seater (City Kabanas) & 83.6 & 78.8 & No Music \\
\hline 3 & 14-Seater (Doonholm) & 76.6 & 74.6 & No Music \\
\hline 4 & 14-Seater (Doonholm) & 76.7 & 71.5 & No Music \\
\hline 5 & 14-Seater (Pipeline) & 77.1 & 71.3 & Music \\
\hline 6 & 14-Seater (Pipeline) & 86.6 & 81.6 & $\begin{array}{l}\text { Music/Old/To } \\
\text { uting }\end{array}$ \\
\hline 7 & Bus (2M Doonholm) & 74.6 & 64.6 & Low Music \\
\hline 8 & Bus (2M/Doonholm) & 68.8 & 61.1 & Music \\
\hline 9 & $\begin{array}{ll}\text { Bus } & \text { (City } \\
\text { Shuttle/Utawala) }\end{array}$ & 75.5 & 68.8 & Music \\
\hline 10 & M/Bus (58) & 94.6 & 86.6 & $\begin{array}{l}\text { Moderate } \\
\text { Music }\end{array}$ \\
\hline 11 & $\mathrm{M} / \mathrm{Bus}(58)$ & 91.2 & 76.9 & Low Music \\
\hline 12 & $\begin{array}{l}\mathrm{M} / \text { Bus } \\
\text { (Embassava/Doonholm) }\end{array}$ & 80.3 & 73.9 & Music \\
\hline 13 & $\begin{array}{l}\text { M/Bus } \\
\text { (Embassava/Pipeline) }\end{array}$ & 72.2 & 63.2 & No Music \\
\hline 14 & $\begin{array}{l}\text { M/Bus } \\
\text { (Embassava/Pipeline) }\end{array}$ & 78.8 & 74.8 & $\begin{array}{l}\text { Moderate } \\
\text { Music }\end{array}$ \\
\hline 15 & M/Bus (Kayole) & 94.6 & 88.6 & Music \\
\hline \multicolumn{5}{|c|}{ Nairobi-Nairobi South Route PSVs } \\
\hline $\begin{array}{l}\mathrm{S} / \\
\mathrm{N}\end{array}$ & Type & $\begin{array}{l}\text { LAEq } \\
(\mathrm{dBA})\end{array}$ & $\begin{array}{l}\text { L90 } \\
\text { (dBA) }\end{array}$ & Remarks \\
\hline 1 & 14-Seater (11B) & 78.1 & 72.3 & Low Music \\
\hline 2 & M/Bus (11B) & 77.7 & 74.1 & $\begin{array}{l}\text { Low } \\
\text { Radio/Old }\end{array}$ \\
\hline 3 & M/Bus (11B) & 75.2 & 54.8 & No Music/Old \\
\hline 4 & Bus (City Shuttle/11B) & 76.6 & 70.9 & Low Radio \\
\hline 5 & Bus (Lang'ata) & 80.7 & 66.9 & $\begin{array}{l}\text { Low } \\
\text { Music/Old }\end{array}$ \\
\hline 6 & 14-Seater (Lang'ata) & 82.2 & 75.5 & $\begin{array}{l}\text { Music/No } \\
\text { Passengers }\end{array}$ \\
\hline 7 & 14-Seater (Lang'ata) & 79.4 & 74.1 & $\begin{array}{l}\text { Moderate } \\
\text { Music }\end{array}$ \\
\hline 8 & M/Bus (Rongai) & 82.3 & 77.4 & Music \\
\hline 9 & M/Bus (Rongai) & 81.7 & 76.2 & Music \\
\hline 10 & M/Bus (Karen) & 86.9 & 81.3 & Music \\
\hline 11 & 14-Seater (Karen) & 86.7 & 81.3 & Music \\
\hline 12 & 14-Seater (Karen) & 86.9 & 81.4 & Music \\
\hline 13 & M/Bus (11B) & 96.5 & 90.3 & Music \\
\hline 14 & Bus (Ngong) & 78.9 & 75.3 & Low Music \\
\hline 15 & M/Bus (Ngong) & 96.5 & 90.1 & Music/Touting \\
\hline
\end{tabular}

\section{References}

[1] Government of Kenya (2009). The Environmental Management and Coordination (Noise and Excessive Vibration Pollution) (Control) Regulations, 2009. Legal Notice No. 61.

[2] Ahmad, K., (1998). A study of noise pollution in Dhaka City, Department of Environment (DOE), Bangladesh.

[3] National Environmental Management Authority, Kenya, NEMA (2011). Assessment of Compliance to Noise and Excessive Vibration Regulations, 2009 in Nairobi Province. Nairobi, Kenya: NEMA.

[4] Sincero, A.P. \& Sincero, A.G. (1995). Environmental Engineering: A Design Approach. Prentice Hall. 
[5] Boldin, et al, (2012). Survey context and question wording affects self-reported annoyance due to road traffic noise: a comparison between two cross-sectional studies. Environmental Health, 11(14), pp. 234-239.

[6] Salvato, E.L. (2003). Environmental Engineering (Fifth Edition). John Wiley \& Sons, Inc: Hoboken, New Jersey.

[7] Alam, J. B. (2006). Study on traffic noise level of sylhet by multiple regression analysis associated with health hazards, Iranian Journal of Environmental Health, Science and Engineering, 3(2), pp.71-78.

[8] Ehrampoush, M.H., Halvani, H.G., Barkhordari, A. \& Zare, M (2012). Pollution in urban environments: A study in Yazd City, Iran. Pol. J. Environ. Stud. 21(4), pp.1095-1100.

[9] Goines, L. \& Hagler, L. (2007). Noise Pollution: A modern plague. Southern Medical Journal, 100(3), pp. 2345-2356.

[10] Pakistan Environmental Program (2006). Measurement of Noise levels at different locations of Rawalpindi and Islamabad [Online] Available at $<$ www.environment.gov.pk/pub-pdf/noise $\% 20 \%$ study $\% 20$ isbrpindi.pdf $>$ [Accessed October 23 2013].

[11] Ityavyar, E.M. \& Tyav, T.T. (2013). Environmental Pollution in Nigeria: The Need for Awareness Creation for Sustainable Development. Journal of Research in Forestry, Wildlife and Environment, 4(2), 1-14.

[12] Ochuko, A. (2013). Evaluation of environmental noise pollution in Abuja, the capital city of Nigeria. IJRRAS, 4(2), pp. 470-477.

[13] Matagi,S.V.(2002).Some issues of environmental concern in Kampala, the capital city of Uganda. Environmental Monitoring and Assessment, 77(1), 121-138.

[14] Samagwa, D., Mkoma, S.L. \& Tungaraza, C. (2009). Investigation of Noise Pollution in Restaurants in Morogoro Municipality,Tanzania, East Africa. Journal of Applied Sciences and Environmental Management, 13(4), 29 - 33.

[15] Liu, D. (1999). Environmental Engineers Handbook: Noise Pollution. CRC Press LLC: New Jersey.Piccolo, A., Plutino, D. \& Cannistraro, G. (2005). Evaluation and analysis of the environmental noise of Messina, Italy. Applied Acoustics, 66(1), 447-465.

[16] Richard, L., Pierre, S.T. \& Maguire, D.J. (2004). The impact of A-weighting Sound Pressure Level measurements during the evaluation of noise exposure. MARC Inc: UK.

[17] Bies, D.A. \& Hansen, C.H. (1996). Engineering Noise Control: Theory and Practice (2nd Edition). E and FN SPON: London.

[18] Bruel, A. \& Kajer, C. (1984). Measuring Sound. Larson and Son Printers: Denmark.

[19] EPA South Australia (2009). Guidelines for the use of the Environment Protection (Noise) Policy, 2007. Government of Australia.

[20] Gary, W.E., Lercher, P., Meis, M., Ising, Harmut \& Kofler, W.W. (2001). Community noise exposure and stress in children. Journal of Acoustical Society of America, 109(3), pp.1023-1027.

[21] I-INCE (2011). Guidelines for community noise impact assessment and mitigation. Final report of the I-INCE Technical Study Group on Community Noise: Environmental Noise Impact Assessment and mitigation, March 2011.

[22] World Health Organization (1999) Guidelines for Community Noise. United Nations: Geneva, Switzerland.

[23] World Health Organization WHO (2009). Night Noise Guidelines for Europe. WHO Regional Office in Europe: UK.

[24] United States Environmental Protection Agency, EPA (1974). Information on Levels of environmental noise requisite to protect public health and welfare with an adequate margin of safety. US Government Printing Office: Washington DC.

[25] Jamir, L., Nongkynrih, B., \& Kumar, S.G. (2014) Community noise pollution in urban India: Need for public health action. Indian Journal of Community Medicine. 39(1), pp. 8-12.

[26] Olayinka, O.S. (2012). Noise map: Tool for abating noise pollution in urban areas. Open Access Scientific Reports. 1(3), pp. 1-7.

[27] Vijay, E.L. (2015). Assessment of honking impact on traffic noise in urban traffic environment of Nagpur, India. Journal of Environmental Health Science \& Engineering, 13(10), pp. 1-9.

[28] Balashanmugam, P., Ramanathan, A.R., Nehrukumar, V. \& Balasubramaniyan, K. (2013). Assessment of noise pollution in Chidambaram town. International Journal of Research in Engineering and Technology, 2(10), pp. 85-93.

[29] Freire, S. \& Gomes, N. (2013). Advancing environmental noise pollution analysis in urban areas by considering the variation of population exposure in space and time. International Archives of the Photogrammetry, Remote Sensing and Spatial Information Sciences, XL-4(W1), pp.155160.

[30] Fadairo, G. (2013). Urban center's noise pollution: A case study of Akure, Nigeria. British. Journal of Arts and Social Sciences, 14(2), pp. 125-132.

[31] Rosenhouse, G. (2012): The essence of noise in nature with reference to acoustics. In Hernandez and Brebbia (Eds) Design and Nature VI. TheWITpress: United Kingdom.

[32] Momir, R.P., \& Darko, I.M. \& Dragan, S.C. Measurement and evaluation of the environmental noise levels in the urban areas of the city of Nis (Serbia). Environmental Monitoring \& Assessment, 186(1), pp. 1157-1165.

[33] Tandel, B., Macwan, J. \& Ruparel, P.N. (2012). Urban Corridor Noise Pollution: A case study of Surat city, India. 2011 International Conference on Environment and Industrial Innovation IPCBEE vol.12 (2011) IACSIT Press, Singapore.

[34] Kim, M., Seo, I.C., Jeong C.S., Holt, B.J., Park, T.H., Ko, J.H. \& Croft, J.B. (2012). Road traffic noise: annoyance, sleep disturbance, and public health implications. American Journal of Preventive Medicine, 43(4), pp. 1211-1221. 